\title{
EVALUATION OF THE EFFECT OF SINGLE BOLUS DOSE OF INTRAVENOUS DEXMEDETOMIDINE IN SPINAL ANAESTHESIA FOR LOWER LIMB SURGERIES.
}

\author{
Paudel $B,{ }^{1 *}$ Rai $P^{2}$ Tiwari $R,{ }^{3}$ Gautam $S,{ }^{3}$ Paudel $S,{ }^{4}$ Shubham ${ }^{2}$
}

\begin{abstract}
Affiliation
1. Assistant Professor, Department of Anesthesiology, Critical care and Pain medicine, Nobel Medical College and Teaching Hospital, Biratnagar, Nepal

2. Consultant, Department of Anesthesiology, Critical care and Pain medicine, Nobel Medical College and Teaching Hospital, Biratnagar, Nepal

3. Resident, Department of Anesthesiology, Critical care and Pain medicine, Nobel Medical College and Teaching Hospital, Biratnagar, Nepal

4. Medical Officer, Department of Anesthesiology, Critical care and Pain medicine, Nobel Medical College and Teaching Hospital
\end{abstract}

\section{ARTICLE INFO}

Received : 09 March, 2020
Accepted : 27 April, 2020
Published : 30 June, 2020

(C) Authors retain copyright and grant the journal right of first publication with the work simultaneously licensed under Creative Commons Attribution License CC - BY 4.0 that allows others to share the work with an acknowledgment of the work's authorship and initial publication in this journal.

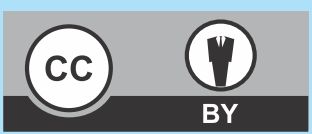

ORA 167

DOI: https://doi.org/10.3126/bjhs.v5i1.29636

\section{* Corresponding Author}

Dr. Bandana Paudel

Assistant Professor

Department of Anesthesiology, Critical Care and Pain Medicine Nobel Medical College and Teaching Hospital Biratnagar, Nepal

Email:dr.bandana.nobel@gmail.com ORCID ID: https://orcid.org/0000-0001-8225-0983

\section{Citation}

Paudel B, Rai P, Tiwari R, Gautam S, Paudel S, Shubham. Evaluation of The Effect of Single Bolus Dose of Intravenous Dexmedetomidine in Spinal Anaesthesia for Lower Limb Surgeries. BJHS 2020;5(1)11:970-975.

\section{ABSTRACT \\ Introduction}

The use of intrathecal adjuvants in spinal anaesthesia in enhancing and prolonging it's action has been well established and is widely used for surgery below the umbilicus. Dexmedetomidine, a selective $\alpha_{2} A$ receptor agonist is a suitable adjuvant due to its selective activity.

\section{Objectives}

To evaluate the effect of a single bolus dose of intravenous dexmedetomidine as an adjuvant in cases undergoing lower limb surgeries under spinal anaesthesia.

\section{Methodology}

One hundred patients posted for lower limb surgery under spinal anaesthesia with hyperbaric bupivacaine, were equally divided into two groups. In group $D$, in addition to spinal, intravenous dexmedetomidine $0.5 \mathrm{mcg} / \mathrm{kg}$ over 10 min was given whereas group $C$ patients received spinal and intravenous normal saline.

\section{Results}

The onset of sensory and motor block was faster in group $D$ (2.09 $\pm 0.71 \mathrm{~min}, 3.18 \pm 1 \mathrm{~min})$ compared to group C (3.5 \pm $0.82 \mathrm{~min}, 6.19 \pm 1.87 \mathrm{~min}$ ) which was statistically significant . The duration of sensory and motor block was also significantly prolonged in Group D (174.5 $\pm 14.04 \mathrm{~min}, 133.4 \pm 10.42 \mathrm{~min})$ as compared to Group C(138.2 $\pm 11.51 \mathrm{~min}, 120.4 \pm 8.8 \mathrm{~min})$. The duration of analgesia in Group D (225.3 $\pm 20.11 \mathrm{~min})$ was prolonged when compared to Group C $(168.3 \pm 15.11)$.

\section{Conclusion}

Intravenous dexmedetomidine as a single bolus dose before spinal anaesthesia can fasten the onset of sensory and motor block, prolongs the duration of sensory and motor block and also increased the duration of analgesia.

\section{KEY WORDS}

Adjuvants; analgesia; bupivacaine; dexmedetomidine; lower extremity; pain management; spinal anesthesia. 


\section{INTRODUCTION}

Post-operative pain still remains the most common type of acute pain and is dreaded by all patients undergoing surgery. Analgesia for post-operative pain control is essential and insufficient post-operative pain control can produce various effects on quality of life, prolong the recovery time and decreases patient satisfaction. ${ }^{1}$ Various types of analgesia regimens are used for attenuation of post-operative pain. Insufficient post-operative pain may activate the sympathetic nervous system and hence contribute to increased myocardial oxygen consumption which may further lead to myocardial ischemia and infarction leading to decrease in myocardial oxygen supply. ${ }^{2}$ Uncontrolled post-operative pain is a major concern for an anaesthesiologist as the patients are not pain free and are dissatisfied.

Spinal anaesthesia is commonly used for surgeries below the umbilicus. ${ }^{3}$ Adjuvants with opioids such as fentanyl, morphine or buprenorphine are sometimes added to improve and enhance the quality and duration of block. The adjuvants added to local anaesthetics prolong the effects of the drug and enhance post-operative pain relief. ${ }^{4}$ Nonopioids adjuvants like clonidine and dexmedetomidine also prolong the effects of the drug. ${ }^{5}$ Only few studies have shown use of intravenous dexmedetomidine and clonidine to enhance and prolong the effect of spinal anaesthesia. ${ }^{6}$ Intravenous adjuvants also decrease the sympathetic tone and stress response to surgery and anaesthesia apart from sedation and analgesia. ${ }^{7}$ At the substantia gelatonisa, stimulation of $\alpha_{2}$ receptors in the spinal cord leads to inhibition of the release of substance P contributing to their analgesic action. ${ }^{8}$

Dexmedetomidine, a selective $\alpha_{2}$ A receptor agonist have shown to be more suitable than clonidine as an adjuvant in spinal anaesthesia and can potentiate its action. ${ }^{9}$ The efficacy of intravenous dexmedetomidine in prolonging the action of intrathecal local anaesthetics in addition to providing sufficient post-operative analgesia has been seen in only a few studies. ${ }^{10}$ The present study is an attempt to evaluate the effect of single bolus dose of intravenous dexmedetomidine in spinal anaesthesia with $0.5 \%$ hyperbaric bupivacaine in patients undergoing lower limb surgeries.

\section{METHODOLOGY}

A prospective randomized double blind study was conducted in 100 patients after ethical clearance from the institutional review committee. Informed and written consent was taken. Patients belonged to ASA I and II, aged 16-60 years and posted for lower limb surgery at Nobel Medical College over a period of one yearfrom August 2018 to August 2019. The sample size of this study was calculated with reference from similar study done in India, for standard deviation $(\sigma)=2.52$ and desirable error $(d)=1^{24} \mathrm{We}$ calculated the sample size with $95 \%$ confidence interval $\left(Z_{1}-a / 2\right)=1.96$. So the minimum sample size per group is 50 , making a total of 100 for two groups. Patients of ASA III and
IV, patients on calcium channel blockers, ACE inhibitors, or clonidine, patients on sedatives, opioids or antidepressants, any allergy to study drugs and contraindications to spinal anaesthesia were excluded from our study.

A total of 100 patients were divided into two groups of 50 each, viz. group D (dexmedetomidine) and group C (control) using sealed envelope technique. Routine pre-anaesthetic check-up was done a day prior to surgery and all patients were explained about the anaesthetic technique and prescribed tab ranitidine $150 \mathrm{mg}$ orally on the evening prior to surgery. Nil per oral for at least 8 hours prior to surgery was maintained. After briefing the patients about the procedure in the operative room, an $18 \mathrm{G}$ intravenous cannula was inserted in the non-dominant hand and ringer lactate (RL) was infused at a rate of $20 \mathrm{ml} / \mathrm{kg}$. Standard ASA monitors were attached. Baseline heart rate, blood pressure, oxygen saturation and ECG were recorded. The anaesthetic nurse was blinded in the randomization schedule and the nurse used an identical syringe to prepare both control and study drug. Using a sealed envelope technique, the patients were randomly divided into two groups. Group D received dexmedetomidine $0.5 \mathrm{mcg} / \mathrm{kg}$ and group $C$ received normal saline. Both study and control drugs were premixed to a total volume of $30 \mathrm{ml}$ and given intravenously over $10 \mathrm{~min}$ as a single bolus dose by an anaesthetist not involved in the study. Under all aseptic precautions spinal anaesthesia was given with $3 \mathrm{ml}$ of $0.5 \%$ hyperbaric bupivacaine. After SAB, vitals were recorded every 2 min for first $10 \mathrm{~min}$ then every $5 \mathrm{~min}$ till the end of surgery and then every $15 \mathrm{~min}$ in post anaesthesia care unit (PACU). In our study hypotension was defined as systolic $\mathrm{BP}<90 \mathrm{mmh}$ from the baseline. Bradycardia was defined as heart rate $<50$ beats/min. Hypotension was treated with intravenous fluids and incremental IV mephentermine $6 \mathrm{mg}$. Bradycardia was treated with IV atropine $0.6 \mathrm{mg}$. Oxygen was supplemented via simple face mask at $5 \mathrm{~L} / \mathrm{min}$.Other side effects like nausea and vomiting were not found in the study.

Sensory blockade was checked in midaxillary line with an alcohol swab. Onset of sensory block and sensory recovery were noted. Sensory blockade was assessed every 2 min for the first $10 \mathrm{~min}$ and then every $15 \mathrm{~min}$ during surgery and post operatively. Modified bromage scale $(0=$ able to move hip, knee and ankle; $1=$ unable to move hip but able to move knee and ankle; $2=$ unableto move hip and knee and but able to move ankle; 3=unable to move hip, knee and ankle) was used to assess the intensity of motor blockade. Onset of motor block and recovery were noted. Motor blockade was assessed every 2 min before the start of surgery and then every $15 \mathrm{~min}$ in post anaesthesia care unit. All the duration were calculated considering the time of spinal injection as time zero. Duration of analgesia was considered as time from the onset of sensory block to the time of administration of first rescue analgesics which was administered when the visual analogue scale (VAS) was $>3$. Throughout the study, the level of sedation was recorded using Ramsay Sedation 
Score(RSS).Patients were discharged from PACU after modified bromage scale was zero and sensory regression to S1.

Analysis of data was done using SPSS windows version 21.0 Armonk NY: IBM Corp. Mean, standard deviation and \% were calculated and expressed with graphical and tubular presentation for descriptive statistics. For inferential statistics Chi square test and independent $t$ test were applied to find out significant differences between the two groups and other selected variables at $95 \%$ confidence interval where $p$ considered as $<0.05$ was statistically insignificant.

\section{RESULTS}

\section{DEMOGRAPHICDATA}

Patients on both side were comparable according to age, gender, weight, ASA physical status as shown on Table no. 1.

Table 1: Demographic Data
\begin{tabular}{|l|c|c|c|}
\hline Variable & Group D & Group C & p-value \\
\hline $\begin{array}{l}\text { Mean Age } \\
\pm \text { SD (yrs) }\end{array}$ & $35.44 \pm 12.36$ & $35.8 \pm 12.67$ & 0.886 \\
\hline Gender (M/F) & $40 / 10$ & $36 / 14$ & 0.349 \\
\hline $\begin{array}{l}\text { Mean weight } \\
\pm \text { SD (Kg) }\end{array}$ & $58.6 \pm 6.13$ & $58.84 \pm 5.79$ & 0.841 \\
\hline ASA (I/II) & $35 / 15$ & $39 / 11$ & 0.362 \\
\hline
\end{tabular}

\section{Spinal Anesthesia}

The mean onset of sensory block was faster in dexmedetomidine group (2.09 $\pm 0.71 \mathrm{~min}$ ) compared to control group (3.5 \pm 0.82 min)which was statistically significant $(P<0.001)$. The mean duration of sensory block was prolonged in dexmedetomidine group (174.5 \pm 14.04 $\mathrm{min}$ ) compared to control group (138.2 $\pm 11.51 \mathrm{~min})$ which was statistically significant $(P<0.001)$.The mean onset of motor block was faster in dexmedetomidine group (3.18 \pm 1 $\mathrm{min})$ compared to control group (6.19 $\pm 1.87 \mathrm{~min})$ which was statistically significant $(P<0.001)$. The mean duration of motor block was prolonged in dexmedetomidine group (133.4 $\pm 10.42 \mathrm{~min}$ )compared to control group (120.4 \pm 8.8 min)which was statistically significant $(P<0.001)$.In dexmedetomidine group, the mean duration of analgesia (from the time of intrathecal deposition of drug till the administration of rescue analgesia) was $225.3 \pm 20.11 \mathrm{~min}$. In control group, the mean duration of analgesia was $168.3 \pm$ $15.11 \mathrm{~min}$. The duration of analgesia was significantly higher in dexmedetomidine group when compared to control group $(p<0.001)$.

Table 2: Motor and Sensory effects
\begin{tabular}{|l|c|c|c|}
\hline $\begin{array}{l}\text { Mean time in min } \pm \text { SD } \\
\text { Eg: onset of sensory } \\
\text { block }\end{array}$ & Group D & Group C & p-value \\
\hline $\begin{array}{l}\text { Mean onset time of } \\
\text { sensory block in } \\
\text { min } \pm \text { SD }\end{array}$ & $2.09 \pm 0.71$ & $3.5 \pm 0.82$ & $<0.001$ \\
\hline $\begin{array}{l}\text { Mean duration of } \\
\text { sensory block in } \\
\text { min } \pm \text { SD }\end{array}$ & $174.5 \pm 14.04$ & $138.2 \pm 11.51$ & $<0.001$ \\
\hline $\begin{array}{l}\text { Mean onset time of } \\
\text { motor block in } \\
\text { min } \pm \text { SD }\end{array}$ & $3.18 \pm 1$ & $6.19 \pm 1.87$ & $<0.001$ \\
\hline $\begin{array}{l}\text { Mean duration of motor } \\
\text { block in min } \pm \text { SD }\end{array}$ & $133.4 \pm 10.42$ & $120.4 \pm 8.8$ & $<0.001$ \\
\hline $\begin{array}{l}\text { Mean duration of } \\
\text { analgesia in min } \pm \text { SD }\end{array}$ & $225.3 \pm 20.11$ & $168.3 \pm 15.11$ & $<0.001$ \\
\hline
\end{tabular}

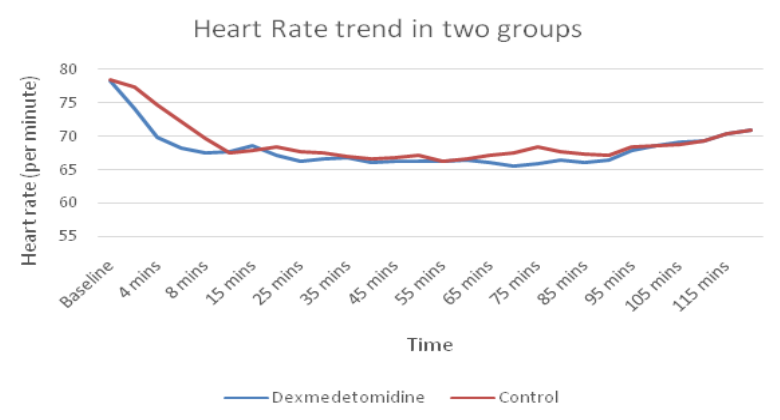

Figure 1: Heart Rate Trend

Only decrease in heart rate and blood pressure were the side effects seen in the patients under study. The lowest HR was $45 \mathrm{bpm}$ in group $D$. The lowest SBP was $81 \mathrm{mmhg}$ in group $D$ and the lowest DBP was $44 \mathrm{mmhg}$ in group C. Although decrease in heart rate was seen slightly more in dexmedetomidine Group and decrease in blood pressure in control group its distribution was however not statistically significant as shown in the graph 1 and 2 .

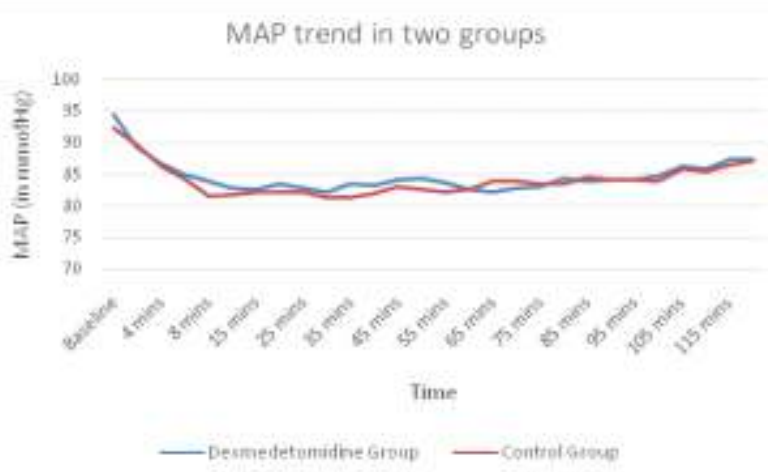

Figure 2: MAP Trend 


\section{DISCUSSION}

Drugs like epinephrine, phenylephrine, magnesium sulphate, sodium bicarbonate, neostigmine, $\alpha_{2}$ agonists like clonidine and dexmedetomidine have been used as adjuvants to local anaesthetics to prolong the duration of spinal anesthesia. ${ }^{4}$ Among them clonidine, an $\alpha_{2}$ agonist is widely used by oral, intrathecal, and intravenous routes as an adjuvant to prolong the duration of spinal anesthesia. ${ }^{1}$ Recent studies have shown the efficacy of both intrathecal and intravenous dexmedetomidine in prolonging the duration of spinal anesthesia. ${ }^{18}$ Dexmedetomidine is a more suitable adjuvant to spinal anaesthesia compared to clonidine as it has more sedative and analgesic effects due to more selective $\alpha_{2} A$ receptor agonist activity. ${ }^{1}$ Added advantage of dexmedetomidine is that it does not have any direct effects on the heart. In the coronary circulation, dexmedetomidine causes a dose-dependent increase in coronary vascular resistance and $\mathrm{O}_{2}$ extraction, but the supply/demand ratio is unaltered. ${ }^{19}$ After the administration of dexmedetomidine a biphasic cardiovascular response has been described. A bolus of $1 \mu \mathrm{g} / \mathrm{kg}$ results in a transient increase in BP and a reflex decrease in HR. This initial response is attributed to the direct effects of $\beta$-adrenoceptor stimulation of the vascular smooth muscle. This response can be attenuated by a slow infusion over $10 \mathrm{~min}$, which results in stabilization of the HR and BP 10-15\% below baseline values. ${ }^{16}$ Intravenous and intrathecal injection of dexmedetomidine produces analgesia by acting at laminae VII and VIII of ventral horns of the spinal cord. ${ }^{17}$ The drug also acts at locus ceruleus and dorsal raphe nucleus to produce sedation and analgesia. ${ }^{18}$ This supra spinal action explains the prolongation of spinal anaesthesia after intravenous dexmedetomidine.

Different doses ranging from 0.2 to $10 \mu \mathrm{g} / \mathrm{kg} / \mathrm{h}$ of intravenous dexmedetomidine have been studied in the past. ${ }^{19}$ Dexmedetomidine when used in higher doses produces significant hemodynamic instability like hypotension and bradycardia. ${ }^{20}$ Aantaa RE et al. concluded that the optimal dose of dexmedetomidine for single dose intravenous premedication in minor surgery appears to be in the range of 0.33 to $0.67 \mu \mathrm{g} / \mathrm{kg}$. ${ }^{21}$ To make the study uniform we selected a dose of $0.5 \mu \mathrm{g} / \mathrm{kg}$ by intravenous route which was administered slowly over a period of 10 minutes prior to administer of spinal anaesthesia. Similar dose was also used before by Jaakola MLet al. and observed moderate analgesia. ${ }^{22}$

In the present study single bolus dose of $0.5 \mu \mathrm{g} / \mathrm{kg}$ of dexmedetomidine has been found to accelerate the onset of sensory block (2.09 $\pm 0.71 \mathrm{~min}$ )compared to control group (3.5 $\pm 0.82 \mathrm{~min}$ ) Similar results were also reported by Harsoor SS et al. ${ }^{23}$ and Reddy $\mathrm{M}$ et al. ${ }^{24}$ who hypothesized that faster onset may be due to $\alpha-2$ receptor activation induced inhibition of nociceptive impulse transmission. But, Tekin M et al. ${ }^{11}$, Elcicek K et al. ${ }^{25}$ and Upadhyay S et al ${ }^{26}$ found that time for onset of sensory blockade was not significantly altered by the use of dexmedetomidine.

Statistically significant prolongation of sensory block, i.e in terms of regression of spinal duration (174.5 $\pm 14.04 \mathrm{~min})$ was observed in the dexmedetomidine group compared to control group (138.2 $\pm 11.51 \mathrm{~min})$. Almost similar results were also observed by several authors, viz. by Whizar-Lugo $\mathrm{V}$ et al. ${ }^{28}$, Kaya FN et al. ${ }^{29}$, Hong JY et al. ${ }^{30}$, Harsoor SS et al. ${ }^{23}$, Kubre J et al. ${ }^{31}$ and Reddy VS et al. ${ }^{14} \mathrm{Jorm} \mathrm{CM}$ et al attributed this effect to the unique property of dexmedetomidine on locus ceruleus located at the brain stem. ${ }^{28}$ Inhibition of locus ceruleus results in disinhibition of the noradrenergic nuclei and applied descending effect on nociception in the spinal cord. ${ }^{18}$

In the present study, the mean time for onset of motor blockade was significantly shorter in dexmedetomidine group (3.18 $\pm 1 \mathrm{~min}$ )when compared to control group (6.19 $\pm 1.87 \mathrm{~min}$ ). This result is consistent with Kanazi GE et al. , AlMustafa MM et al. ${ }^{32}$ Esmaoglu A et al. ${ }^{33}$ Chandrashekharappa Ket al. ${ }^{34}$ and Reddy VS et al. ${ }^{14}$ who compared dexmedetomidine and clonidine with placebo. However, in studies by Kaya FN et al. ${ }^{29}$ and Reddy $\mathrm{M}$ et al. ${ }^{24}$ the mean time for onset of motor blockade was comparable in dexmedetomidine and control groups which was not statistically significant.

The mean duration of motor block was prolonged in dexmedetomidine group (133.4 $\pm 10.42 \mathrm{~min}$ ) compared to control group (120.4 \pm 8.8 mins) but not as long as that of sensory block. Similar prolongation of motor blockade was reported in previous studies conducted by Hong et al. $^{30}$ and Kubre J et al. ${ }^{31}$ Similarly, Tekin $\mathrm{M}$ et al. ${ }^{11}$, Whizar-Lugo $\mathrm{V}$ et al. ${ }^{28}$, Al Mustafa MM et al. ${ }^{32}$, Elcicek K et al. ${ }^{25}$ and Santpur $\mathrm{MU}$ et al. ${ }^{35}$ also found that complete resolution of motor blockade was significantly prolonged in the dexmedetomidine group where they used loading and infusion dose of dexmedetomidine. But they used larger dose of bupivacaine. The mechanism of motor block produced by $\alpha_{2}$-agonist is unclear but some evidence showed that clonidine may produce direct inhibition of impulse conduction in the large, myelinated $A \alpha$ fibers and the $50 \%$ effective concentration (EC50\%) measured was found to be approximately fourfold of that in small, unmyelinated $C$ fibers. ${ }^{32}$ The same mechanism may be applicable to dexmedetomidine, which explains the more sensory than motor block prolongation in dexmedetomidine group compared to control group. Contrary to the above studies, Kaya FN et al. ${ }^{29}$, Reddy VS et al. ${ }^{14}$ reported no significant prolongation in the duration of motor block with dexmedetomidine group though sensory block was prolonged which they thought that like clonidine motor and sensory block was concentration dependant and sensory fibres might be more inhibited than motor fibres at the same concentration of drugs.

The duration of analgesia i.e. time from the onset of sensory block to the time of administration of first rescue analgesia in dexmedetomidine group (225.3 $\pm 20.11 \mathrm{~min})$ was more compared to control group (168.3 $\pm 15.11 \mathrm{~min}$ ) which was statistically significant. The observation was also consistent with the study done by Hong JY et al. ${ }^{30}$, Harsoor SS et al. ${ }^{23}$, Reddy $\mathrm{M}$ et al. ${ }^{24}$ and Reddy VS et al. ${ }^{14}$ Similarly, Al-Mustafa 
MM et al. ${ }^{32}$, Kaya FN et al. ${ }^{29}$ and Kubre J et al. ${ }^{31}$ also found that the time to first request for postoperative analgesic was significantly prolonged and the $24 \mathrm{hrs}$ mean requirement of analgesics was significantly less in the dexmedetomidine group, which they attributed to the action at spinal, supraspinal, direct analgesic and/or vasoconstricting actions on blood vessels.

Hemodynamic parameters HR, SBP, DBP and MAP were stable during the study period. Although the incidence of decrease in heart rate was more in the dexmedetomidine group (12\%) compared to control group (4\%) but was not statistically significant $(p=0.140)$. The result of the present study correlates well with the result published by Kubre J et al. ${ }^{31}$ The lower HR observed in dexmedetomidine group could be explained by the postsynaptic activation of $\alpha_{2}$ adrenoceptors in the CNS, which results in a decrease in sympathetic activity and circulating levels of catecholamines. Studies done by Aantaa RE et al. ${ }^{21}$ also support these finding. Intraoperative and postoperative bradycardia and hypotension were also observed by Tekin $\mathrm{M}$ et al. ${ }^{11}$, Al Mustafa MM et al. ${ }^{32}$ and Hong JY et al. ${ }^{30}$ with dexmedetomidine, but they used the drug throughout the procedure by continuous intravenous infusion.

In the present study no statistically significant hypotension and bradycardia were observed in both the groups. The incidence of side effects like hypotension and bradycardia requiring treatment were comparable in both the groups and was not statistically significant. These findings were consistent with findings of Reddy VS et al. ${ }^{14}$ and Reddy M et al. ${ }^{24}$

\section{CONCLUSION}

We conclude that dexmedetomidine $0.5 \mu \mathrm{g} / \mathrm{kg}$ bolus infusion prior to subarachnoid block with hyperbaric bupivacaine quickens the onset of sensory and motor block, prolongs the duration of sensory and motor, prolonged duration of analgesia with minimal changes in hemodynamic profile and acceptable side effects thereby making dexmedetomidine an effective adjuvant for spinal anaesthesia.

\section{RECOMMENDATIONS}

This study has shown that IV dexmedetomidine is a useful adjunct for spinal anesthesia with hyperbaric bupivacaine. However, its use in children and elderly patients need further evaluation. The cost factor of dexmedetomidine should also be considered during its use.

\section{LIMITATION OF THE STUDY}

1. Patients with ASA physical status grade I and II were only involved in this study. So these results might not be applicable in patients with higher grades.

2. The sample size of the study was small and was carried out at only one institution which was too small for broad generalization.

3. Extremes of age were not included in this study. Result may vary in children and elderly patients.

4. Emergency lower limb surgeries were not included in this study.

\section{ACKNOWLEDGEMENT}

We would like to acknowledge our HOD, Prof. C.R Das for his guidance and the Department of Anaesthesiology, Critical Care and Pain Management, who directly or indirectly helped us to complete the study.

\section{CONFLICT OF INTEREST}

None

\section{FINANCIALDISCLOSURE}

None

\section{REFERENCES}

1. Kehlet $\mathrm{H}$, Jensen TS, Woolf $\mathrm{CJ}$. Persistent postsurgical pain: risk factors and prevention. The Lancet. 2006 May 13;367(9522):161825.DOI:10.1016/S0140-6736(06)68700-X

2. Sarma J, Narayana PS, Ganapathi P, Shivakumar MC. A comparative study of intrathecal clonidine and dexmedetomidine on characteristics of bupivacaine spinal block for lower limb surgeries. Anesthesia, essays and researches. 2015 May;9(2):195-207. DOI:10.4103/0259-1162.153763

3. Sule AZ, Isamade ES, Ekwempu CC. Spinal anaesthesia in lower abdominal and limb surgery: A review of 200 cases. Nigerian Journal of surgical research. 2005;7(1):226-30.DOI:10.4314/ njsr.v7i1.12287

4. Swain A, Nag DS, Sahu S, Samaddar DP. Adjuvants to local anesthetics: Current understanding and future trends. World journal of clinical cases. 2017 Aug 16;5(8):307-23. DOI: 10.12998/wjcc.v5.i8.307

5. Ganesh M, Krishnamurthy D. A comparative study of dexmedetomidine and clonidine as an adjuvant to intrathecal bupivacaine in lower abdominal surgeries. Anesthesia: Essays and Researches. 2018 Apr 1;12(2):539-45DOI: 10.4103/aer.AER_54_18.

6

Kanazi GE, Aouad MT, Jabbour-Khoury SI, Al Jazzar MD, Alameddine MM, Al-Yaman R, Bulbul M, Baraka AS. Effect of low-dose dexmedetomidine or clonidine on the characteristics of bupivacaine spinal block. ActaAnaesthesiologicaScandinavica. 2006 Feb;50(2):222-7.DOI: 10.1111/j.1399-6576.2006.00919.x

7. Rani HL, Upendranath I. Comparative study of intravenous dexmedetomidine plus intrathecal bupivacaine vs intrathecal bupivacaine alone for prolongation of spinal analgesia. Journal of Evolution of Medical and Dental Sciences. 2015 Nov 23;4(94): 15952-9.DOI: 10.14260/jemds/2015/2324.

8. Yabeck-Karam VG, Aouad MM. Perioperative uses of dexmedetomidine. Middle East Journal of Anesthesiology. 2006 Oct;18(6):1043-58.PMID: 17263262

9. GiovannittiJr JA, Thoms SM, Crawford JJ. Alpha-2 adrenergic receptor agonists: a review of current clinical applications. Anesthesia progress. 2015 Mar;62(1):31-8.DOI: 10.2344/00033006-62.1.31

10. Kaur S, Baghla N, Aggarwal H. Is dexmedetomidine a better sedative agent than clonidine in spinal anesthesia?. Anaesthesia, Pain \& Intensive Care. 2016 Oct 1;20(4):451-7.DOI: 10.7860/JCDR/ 2014/9624.4946 
11. Tekin M, Kati I, Tomak Y, Kisli E. Effect of dexmedetomidine IV on the duration of spinal anesthesia with prilocaine: A double-blind, prospective study in adult surgical patients. Current Therapeutic Research. 2007 Sep 1;68(5):313-24DOI: 10.1016/ j.curtheres. 2007.10.006..

12. Pankaj K, Rajan PS. Alpha 2 agonists in regional anaesthesia practice: Efficient yet safe?. Indian Journal of Anaesthesia. 2014 Nov;58(6):681-3.DOI: 10.4103/0019-5049.147127

13. Hamed AM, Talaat SM. Effect of intravenous versus intrathecal lowdose dexmedetomidine on spinal block in lower limb orthopedic surgery. Ain-Shams Journal of Anaesthesiology. 2014 Apr 1;7(2):205-10.DOI: 10.4103/1687-7934.133442

14. Reddy VS, Shaik NA, Donthu B, Sannala VK, Jangam V. Intravenous dexmedetomidine versus clonidine for prolongation of bupivacaine spinal anesthesia and analgesia: A randomized double-blind study. Journal of anaesthesiology, clinical pharmacology. 2013 Jul;29(3):342-7.DOI: 10.4103/09709185.117101

15. Patel CR, Engineer SR, Shah BJ, Madhu S. Effect of intravenous infusion of dexmedetomidine on perioperative haemodynamic changes and postoperative recovery:..A study with entropy analysis. Indian journal of anaesthesia.2012 Nov;56(6):542-6.DOI: 10.4103/0019-5049.104571

16. Bloor BC, Ward DS, Belleville JP, Maze M. Effects of intravenous dexmedetomidine in humans. II. Hemodynamic changes. Anesthesiology. 1992 Dec;77(6):1134-42. DOI: 10.1097/ 00000542-199212000-00014.

17. Al-Oweidi AS, Al-Mustafa MM, Al Ajlouni JM, et al. Intravenous dexmedetomidine or propofol adjuvant to spinal anesthesia in total knee replacement surgery. Jordan Med J. 2011 Apr;45(2):17482.http://dar.ju.edu.jo/jmj

18. Guo TZ, Jiang JY, Buttermann AE, Maze M. Dexmedetomidine injection into the locus ceruleus produces antinociception. Anesthesiology: The Journal of the American Society of Anesthesiologists. 1996 Apr 1;84(4):873-81.DOI: 10.1097/ 00000542-199604000-00015

19. Shukry M, Miller JA. Update on dexmedetomidine: use in nonintubated patients requiring sedation for surgical procedures. Therapeutics and Clinical Risk Management. 2010 Mar 10;6:11121.DOI: $10.2147 / \mathrm{tcrm} .55374$

20. Hall JE, Uhrich TD, Barney JA, Arain SR, Ebert TJ. Sedative, amnestic, and analgesic properties of small-dose dexmedetomidine infusions. Anesthesia\& Analgesia. 2000 Mar 1;90(3):699-705.DOI: 10.1097/00000539-200003000-00035

21. Aantaa RE, Kanto JH, Scheinin M, Kallio AM, Scheinin $H$. Dexmedetomidine premedication for minor gynecologic surgery. Anesthesia and analgesia. $1990 \mathrm{Apr} ; 70(4): 407-13$. doi: 10.4103/2229-516X.136788

22. Jaakola ML, Salonen $M$, Lehtinen $R$, Scheinin $H$. The analgesic action of dexmedetomidine-a novel $\alpha 2$-adrenoceptor agonist-in healthy volunteers. Pain. 1991 Sep 1;46(3):281-5.DOI: 10.1016/ 03043959(91)90111-a

23. Harsoor SS, Rani DD, Yalamuru B, Sudheesh K, Nethra SS. Effect of supplementation of low dose intravenous dexmedetomidine on characteristics of spinal anaesthesia with hyperbaric bupivacaine. Indian journal of anaesthesia. 2013 May;57(3):265-9.DOI: 10.4103/0019-5049.115616
24. Reddy M, Narayanappa AB, Babu S. Effects of single bolus dose of intravenous Dexmedetomidine on intrathecal hyperbaric Bupivacaine: a randomized double blind placebo controlled trial. Journal of Society of Anesthesiologists of Nepal. 2016 Mar 20;3(1):8-12.DOI: 10.3126/jsan.v3i1.14652

25. Elcıcek K, Tekın M, Katı I. The effects of intravenous dexmedetomidine on spinal hyperbaric ropivacaineanesthesia. Journal of anesthesia. 2010 Aug 1;24(4):544-8.DOI: 10.1007/ s00540-010-0939-9

26. Upadhyay S, Samanth U, Tellicherry S, Mallick P. Role of intravenous dexmedetomidine in prolonging postoperative analgesia and quality of block following spinal anaesthesia. A Systemic Review Update. J Pain Relief. 2015 Feb 16;4(2):1-6.DOI: 10.4172/21670846.1000175

27. Jorm CM, Stamford JA. Actions of the hypnotic anaesthetic, dexmedetomidine, on noradrenaline release and cell firing in rat locus coeruleus slices. BJA: British Journal of Anaesthesia. 1993 Sep 1;71(3):447-9.DOI: 10.1093/bja/71.3.447

28. Whizar-Lugo V, Gómez-Ramírez IA, Cisneros-Corral R, MartínezGallegos N. Intravenous dexmedetomidine vs Intravenous clonidine to prolong bupivacaine spinal anesthesia. A doublé blind study. Anestesiaen Mexico. 2007;19(3):143-6.DOI: 10.4103/02591162.174465

29. Kaya FN, Yavascaoglu B, Turker G, Yildirim A, Gurbet A, Mogol EB, Ozcan B. Intravenous dexmedetomidine, but not midazolam, prolongs bupivacaine spinal anesthesia. Canadian Journal of Anesthesia. 2010 Jan 1;57(1):39-45.DOI: 10.1007/s12630-0099231-6.

30. Hong JY, Kim WO, Yoon Y, Choi Y, Kim SH, Kil HK. Effects of intravenous dexmedetomidine on low-dose bupivacaine spinal anaesthesia in elderly patients. Acta Anaesthesiologica Scandinavica. 2012 Mar;56(3):382-7.DOI: 10.1111/j.13996576.2011.02614.x.

31. Kubre J, Sethi A, Mahobia M, Bindal D, Narang N, Saxena A. Single dose intravenous dexmedetomidine prolongs spinal anesthesia with hyperbaric bupivacaine. Anesthesia, essays and researches. 2016 May;10(2):273-7.DOI: 10.4103/0259-1162.174465.

32. Al-Mustafa MM, Badran IZ, Abu-all HM, Al-Barazangi BA, Massad IM, Al-Ghanem SM. Intravenous dexmedetomidine prolongs bupivacaine spinal analgesia. Middle East J Anesthesiol. 2009 Jun;20(2):225-31.PMID: 19583070

33. Esmaoğlu A, Türk S, Bayram A, Akın A, Uğur F, Ülgey A. The effects of dexmedetomidine added to spinal levobupivacaine for transurethral endoscopic surgery. Balkan Medical Journal. 2013 Jun;30(2):186-90.DOI: 10.5152/balkanmedj.2013.7082

34. Chandrashekharappa K, Ravindra CG, Kumara AB, Kiran M. Intravenous Dexmedetomidine Premedication on Spinal Anaesthesia with Hyperbaric Bupivacaine in Patients Undergoing Total Abdominal Hysterectomies.-. International Journal of Health Sciences and Research (IJHSR). 2015;5(8):155-61.

35. Santpur MU, Kahalekar GM, Saraf N, Losari A. Effect of intravenous dexmedetomidine on spinal anaesthesia with $0.5 \%$ hyperbaric bupivacaine in lower abdominal surgeries: a prospective randomized control study. Anesthesia, Essays and Researches. 2016Sep;10(3):497-501.DOI: 10.4103/0259-1162.179319 